\title{
Cursos de graduação em ciências ambientais no Brasil: uma análise curricular comparativa
}

A ciência ambiental é relativamente recente no cenário epistemológico e metodológico das ciências consideradas tradicionais (Exatas Humanas e da Natureza), assim como os cursos de graduação que levam essa nomenclatura. Pela recente atuação desses cursos no Brasil, e a ausência de Diretrizes Básicas Curriculares (DBC) referente à esse curso, esse trabalho objetiva uma análise comparativa curricular dos cursos de Ciências Ambientais no Brasil. As disciplinas, suas cargas horárias e abordagens foram comparadas entre as universidades e nas diferentes áreas de conhecimento segundo o CNPq. Observou-se que a carga horária variou entre as dez universidades que oferecem o curso, tanto a carga horária total, desde 4012 horas (Unifesp) a 2400 (UFMG), quanto às cargas horárias das disciplinas nas grandes áreas, mostrando as diferenças de abordagens das universidades. Com essa análise pode-se entender que apesar da ausência das DBC, há uma semelhança quanto às grandes áreas do conhecimento abordadas, e ao perfil do egresso que procura ter uma formação interdisciplinar com abordagens transdisciplinares, e as diferenças entre as universidades também se mostraram importantes de modo que mostrem suas singularidades e focos seguindo justamente a proposta de flexibilização das Lei de Diretrizes e Bases da Educação Nacional (LDB).

Palavras-chave: Diretrizes Curriculares; Ciências Ambientais; Interdisciplinaridade.

\section{Undergraduate courses in environmental sciences in Brazil: a comparative curricular analysis}

\begin{abstract}
Environmental science is relatively recent in the epistemological and methodological scenario of the sciences considered traditional (Exact, Human and Nature), as well as the undergraduate courses that carry this nomenclature. Due to the recent performance of these courses in Brazil, and the absence of Basic Curricular Guidelines (BCG) for this course, this work aims at a comparative curricular analysis of the Environmental Science courses in Brazil. The disciplines, their workloads and approaches were compared between universities and in the different areas of knowledge according to CNPq. It was observed that the hours varied between the ten universities that offer the course, both the total workload, from 4012 hours (Unifesp) to 2400 (UFMG), as well as the hourly loads of the disciplines in the large areas, showing the differences of approaches Of universities. With this analysis it can be understood that despite the absence of the BCG, there is a similarity regarding the large areas of knowledge addressed, and the profile of the egress who seeks to have an interdisciplinary formation with transdisciplinary approaches, and the differences between the universities also Showed important in such a way that they show their singularities and focuses following precisely the proposal of flexibilization of the Law of Directives and Bases of National Education (LDB).
\end{abstract}

Keywords: Curricular Guidelines; Environmental Sciences; Interdisciplinarity.

\section{Topic: Educação Ambiental}

Reviewed anonymously in the process of blind peer.
Received: $18 / 07 / 2017$

Approved: 17/10/2017
Letícia Moreira Viesba

Universidade Federal de São Paulo, Brasil http://lattes.cnpq.br/0769389543642677 leticia.viesba@gmail.com

\section{Ana Luisa Vietti Bitencourt}

Université de Caen, França

http://lattes.cnpq.br/1230773059940967

viettib@gmail.com

\section{Zysman Neiman}

Universidade de São Paulo, Brasil http://lattes.cnpq.br/6435341856481082 zysman@physis.org.br
Referencing this:

VIESBA, L. M.; BITENCOURT, A. L. V.; NEIMAN, Z.. Cursos de graduação em ciências ambientais no Brasil: uma análise curricular comparativa. Revista Ibero-Americana de Ciências Ambientais, v.8, n.4, p.198-209, 2017. DOI: http://doi.org/10.6008/SPC2179-6858.2017.004.0017 


\section{INTRODUÇÃO}

A ciência ambiental é relativamente recente no cenário epistemológico e metodológico das ciências consideradas tradicionais (Exatas, Humanas e da Natureza), surgindo durante as últimas décadas do século XX como consequência dos processos de poluição e degradação do meio natural, gerados a partir dos modelos do sistema de produção, da utilização e da crise dos recursos naturais, energéticos e de alimentos (ABRAMOVAY, 2002). Nesse período, ocorreram importantes reflexões sobre relação a das atividades humanas, o crescimento populacional e a exploração dos recursos naturais com o ambiente, em vários países tradicionalmente produtivos industrialmente, como Estados Unidos, Japão e países Europeus ocidentais (NEIMAN, 2013).

Nesse contexto novas questões epistemológicas surgiram para os desafios ambientais, entendidas como dimensões espaço-temporais complexas, demandando abordagens holísticas e métodos interdisciplinares, visando estabelecer bases para uma gestão racional do ambiente (LEFF, 2000). Estes debates promoveram, igualmente, a integração das ciências da natureza, exatas, sociais, econômicas, tecnológicas e culturais (UNESCO, 1986).

A trajetória da ciência ambiental no Brasil vincula-se ao processo de credenciamento de cursos de pós-graduação na área de Ecologia e Meio Ambiente pela Coordenação de Aperfeiçoamento de Pessoal de Nível Superior (CAPES), entre os anos de 1976 a 1996 (COUTINHO, 1996). O credenciamento desses cursos de pós-graduação acompanhou a institucionalização da ecologia no Brasil, seguido de paradigmas teóricometodológicos de cunho interdisciplinar e aproximação entre profissionais das mais variadas formações em torno de um trabalho conjunto e interligado para resolver problemas socioambientais (ROCHA et al., 2002).

Por outro lado, a formação de recursos humanos em nível de graduação na área do meio ambiente, surgiram ao longo dos anos 1980-1990. Os cursos visam a formação de profissionais para atuarem nas áreas do planejamento, da gestão e da engenharia ambiental. Curricularmente, estruturavam-se ora com pressupostos teórico-metodológico vinculados às ciências sociais e econômicas, para planejar e/ou quantificar processos socioeconômicos, ora norteados pelos pressupostos das ciências exatas, como no caso das engenharias, visando avaliar e quantificar processos ambientais. Tais propostas curriculares apresentavam-se distintas das abordagens integradas entre processos físicos, químicos, biológicos, sociais e econômicos, necessária para o pleno entendimento da complexa temática ambiental.

A interdisciplinaridade surge como uma necessidade prática de articulação dos conhecimentos, constituindo um dos efeitos ideológicos mais importantes sobre o atual desenvolvimento das ciências. De princípio positivista, as práticas interdisciplinares desconhecem a existência dos objetos teóricos das ciências; a produção conceitual dissolve-se na formalização das interações e relações entre objetos empíricos. Os fenômenos não são captados a partir do objeto teórico de uma disciplina científica, mas da interação das partes constitutivas de um todo visível.

A interdisciplinaridade propõe a busca das homologias estruturais entre as diversas disciplinas que respondem a diferentes processos da realidade, formalizando-se na Teoria Geral de Sistemas (BERTALANFFY, 2010). Esta visão do conhecimento fez surgir as chamadas 'Ciências Ambientais', que, como sendo um leque 
de disciplinas, especializações e técnicas para uma prática do 'ecodesenvolvimento', não possui um objeto científico propriamento dito (LEFF, 2000). Os princípios da prática 'interdisciplinar' como metodologia unificadora do saber foram transferidos para o campo da teoria, surgindo a aplicação de metodologias de uma ciência em outro campo científico, ou 'transdisciplinaridade' (JAPIASSU, 1976).

Os cursos bacharelados em Ciências Ambientais no Brasil são muito recentes, surgiram apenas a partir de 2002, a partir de um cenário emergente de uma nova graduação para a área ambiental, associada a um novo perfil profissional com características inter e multidisciplinar, com propostas curriculares integradoras, além da inclusão de temas transversais, relevantes para a reflexão e análise das questões ambientais, envolvendo ética, solidariedade, responsabilidade, educação, gestão e cidadania. Temas transversais são entendidos como o conjunto de assuntos e conteúdos de natureza social, não se configuram como disciplinas e possuem características interdisciplinares, sendo tratados de forma transversal na matriz curricular (MEC, 1998).

Vários cursos de graduação em Ciências Ambientais surgiram entre os anos de 2006 a 2010, durante o processo de Reestruturação Expansão das Universidades Federais (REUNI), instituído pelo Decreto no6096/2007. Dentre as várias instituições que aderiram ao Reuni, a Universidade Federal de São Paulo (UNIFESP), implementou bacharelado em Ciências Ambientais, visando à consolidação da proposta políticopedagógica do Campus de Diadema para a área ambiental.

Um dos principais objetivos para a implantação do curso foi a inserção geográfica do campus, contextualizada em múltiplos exemplos e cenários de impactos ambientais, envolvendo a regiões metropolitana de São Paulo e o ABCDMRR (formada pelos municípios de Santo André, São Bernardo do Campo, São Caetano do Sul, Diadema, Mauá, Ribeirão Pires e Rio Grande da Serra), com panoramas de áreas de mananciais e de preservação de remanescentes florestais, circundados por ocupações desordenadas em áreas de risco, lixões, poluentes nos solos e nas águas, lançamentos de gases e material particulado na atmosfera pelo intenso tráfego veicular e atividade industrial.

Em contextos similares, outras universidades brasileiras implementaram o curso de bacharelado em Ciências Ambientais praticamente no mesmo período, destacando-se: Centro Universitário do Pará (CESUPA); Universidade Federal do Ceará (UFC); Universidade Federal Fluminense (UFF); Universidade Federal de Goiás (UFG); Universidade Federal de Minas Gerais (UFMG); Universidade Federal de Pernambuco (UFPE); e Universidade de Brasília (UNB), que possui quatro habilitações: Conservação e Uso da Biodiversidade (UNB 1); Manejo e Conservação de Recursos Hídricos e Solos (UNB 2); Planejamento Ambiental (UNB 3) e Políticas da Sustentabilidade (UNB 4), Universidade Federal do Amapá (UNIFAP), Universidade Federal de São Paulo (UNIFESP), Universidade Federal do Estado do Rio de Janeiro (UNIRIO), e a Faculdade Guarapuava (FG). Destas, duas atualmente, não ofertam o curso, sendo elas: Cesupa e a FG.

O presente trabalho tem como objetivo oferecer uma análise comparativa da estrutura curricular dos cursos de bacharelados em Ciências Ambientais no Brasil, em relação ao leque de disciplinas oferecidas, as abrangências entre diferentes áreas das ciências (exatas, humanas, biológicas, sociais, ecológicas e 
geociências) e as cargas horárias, na perspectiva de verificar possíveis semelhanças e a existência de uma carga horária mínima curricular para a formação do cientista ambiental no país.

\section{METODOLOGIA}

Para análise curricular dos diferentes cursos foi utilizada a metodologia de análise documental, baseada em Pimentel (2001), que é retratada como 'garimpagem', onde o material é coletado, processado e analisado segundo o cruzamento de informações de interesse. Considera-se como informação de interesse, as disciplinas, as áreas do conhecimento envolvidas nas matrizes dos cursos e o número de horas ou créditos, tendo como documentos de base os Planos Políticos Pedagógicos (PPPs) de cada curso. O acesso aos (PPPs) foi obtido por meio de consultas aos dos sites das universidades citadas e, em alguns casos, através de contatos via endereço eletrônico dos coordenadores dos cursos em questão.

Ao todo, foram analisados 11 currículos de cursos de Ciências Ambientais de universidades brasileiras cadastradas no MEC. Dentre a abrangência das informações de interesse, destacam-se as compilações básicas: nome do curso, ano de implementação, perfil do egresso, turno de oferecimento, número de estudantes por turma, duração, carga horária total, disciplina obrigatórias, disciplinas eletivas, atividades complementares, trabalho de conclusão de curso e estágio.

Os dados foram plotados em tabelas a partir do software Excel-Windows 10, considerando-se comparar: a carga horária dos cursos nas diferentes universidades analisadas; a distribuição da carga horária por grandes áreas do conhecimento (segundo as grandes áreas do CNPq) em cada curso e a carga horária das disciplinas em cada curso. As grandes áreas do conhecimento consideradas pelo conjunto de disciplinas oferecidas nos cursos de graduação em Ciências Ambientais são: Ciências Exatas e da Terra; Ciências Agrárias; Ciências Biológicas; Engenharia; Ciências Sociais Aplicadas; Humanas; Multidisciplinar; Metodologias; e Outros. Considera-se neste trabalho na categoria 'Outros' respectivamente as disciplinas de: Seminários; Campo; Projeto Integrado; Língua Portuguesa; e Práticas em Ciências Ambientais. Análise qualitativa e quantitativa dos dados foi obtida através da construção histogramas, que permitiu identificar as tendências curriculares dos cursos de Ciências Ambientais atualmente no Brasil.

\section{RESULTADOS E DISCUSSÃO}

Em relação ao nome dos cursos existem algumas diferenças nas apelações, vinculadas, principalmente ao perfil do egresso, como no caso da UFPE onde o curso é de Biologia, porém apresenta ênfase em Ciências Ambientais. Neste caso o perfil do egresso postula Biólogo com ênfase nas Ciências Ambientais Já na UFMG o curso é denominado de Ciências Socioambientais, e postula como o perfil do egresso um profissional que seja capaz de refletir e intervir nas relações entre a sociedade e o meio ambiente. No CESUPA é de Ciências Ambientais com ênfase em Pericia e Gestão Ambiental, tendo como acréscimo ao perfil do cientista ambiental, a habilidade de atuar como perito e como gestor ambiental. Nas demais universidades analisadas a apelação do curso é Ciências Ambientais e o perfil do egresso se assemelha: 
manejar recursos naturais de forma sustentável, além de possibilitar a condução de trabalhos em equipes multidisciplinares, tendo como pressupostos a integração teórica e prática numa perspectiva inter e transdisciplinar entre as Ciências Exatas e da Terra, BioEcológicas e Humanas (UNIFESP, 2016).

Em relação a implementação desses cursos no Brasil, ocorreu no intervalo entre 2001 e 2010 . Em 2001 foi criado o curso de Biologia com ênfase em Ciências Ambientais na UFPE, em 2004 o CESUPE no Pará foi a primeira universidade a implementar o curso especificamente de ciências ambientais no pais, sendo os demais implementados a partir do REUNI em 2009 nas outras universidades.

No que concerne à distribuição geográfica o cenário atual é que existe o curso de Ciências Ambientais em quase todas uma das regiões do Brasil. Na região norte (houve o da CESUPA no Pará) e UNIFAP no Amapá; no nordeste, o da UFC no Ceará e da UFPE em Pernambuco, no Centro-Oeste o da UFG em Goiás e da UNB em Brasília; no sudeste, o da UFF e UNIRIO no Rio de Janeiro, da UFMG em Minas Gerais e da UNIFESP em São Paulo, e na região sul houve o da FG no Paraná, porém com a desativação do curso da Faculdade Guarapuava a região sul do país ficou sem oferta do curso.

Cinco das universidades oferecem o curso no período noturno (UNIFAP, UNIRIO, UNB, UFMG e UFPE), três delas no diurno - meio período (CESUPA, UFG e UFC) e duas delas oferecem em período integral (UNIFESP e UFF). Os cursos das 10 universidades analisadas, nove delas (90\%) tem no mínimo duração de 4 anos ou mais (sendo a FG, UNIFESP, UNIFAP, UFF, UFC, UNIRIO, UFPE E UFMG com duração de 4 anos e a UFG com duração de 3 a 7 anos), apenas uma (CESUPA) ofereceu o curso com duração mínima de três anos. Apesar de haver uma grande convergência entre os dez cursos para o período mínimo de duração de 4 anos, já em relação a carga horária total varia muito. Os cursos na modalidade integral possuem maior carga horária, como o da Unifesp (4.012 horas) e o da UFF (3.190 horas), conforme se visualiza na figura 1.

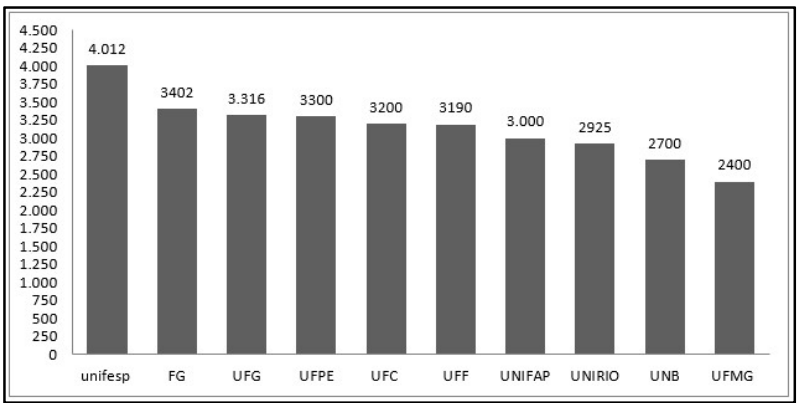

Figura 1: Gráfico da carga horária total dos cursos de graduação em Ciências Ambientais nas universidades brasileiras.

A carga horária dos cursos se divide entre disciplinas obrigatórias, eletivas, atividades complementares, TCC, estágio e atividades de extensão. Apenas a Universidade Federal de Goiás (UFG) destina horas especificas para extensão, todas as demais incluem atividades de extensão na sua carga horária comum, principalmente em atividades complementares.

Algumas das universidades apresentam um panorama de carga horária mais elevada de disciplinas eletivas (cerca de 30\%). Essas possibilitam ao discente ter uma maior flexibilidade na sua formação, como por exemplo o curso CA na UNB, que por meio do conjunto de eletivas cursadas permite 4 habilitações na formação: Conservação e uso da Biodiversidade, Manejo e Conservação de Recursos Hídricos e Solos, Planejamento Ambiental e Políticas da Sustentabilidade. 
Com a alocação das disciplinas em suas respectivas grandes áreas do CNPq foi possível verificar as semelhanças e as diferenças em relação ao percentual das cargas horárias e, com isso, verificar o predomínio das grandes áreas nos cursos de ciências ambientais nas diferentes universidades analisadas, como se pode notar na figura 2. A Figura 2 expressa o percentual das cargas horárias das grandes áreas do conhecimento em cada curso de ciências ambientais, em que se destaca, em primeiro, Ciências Exatas e da Terra entre 30 a $54 \%$ na maioria dos cursos. Percentuais menores, 5 a $18 \%$ entre os cursos da UFMG, UFPE, CESUPA e UNIFAPA. Pode-se observar que essa área possui, em geral, uma carga horária significativa, demonstrando uma importante base na formação do cientista ambiental brasileiro.

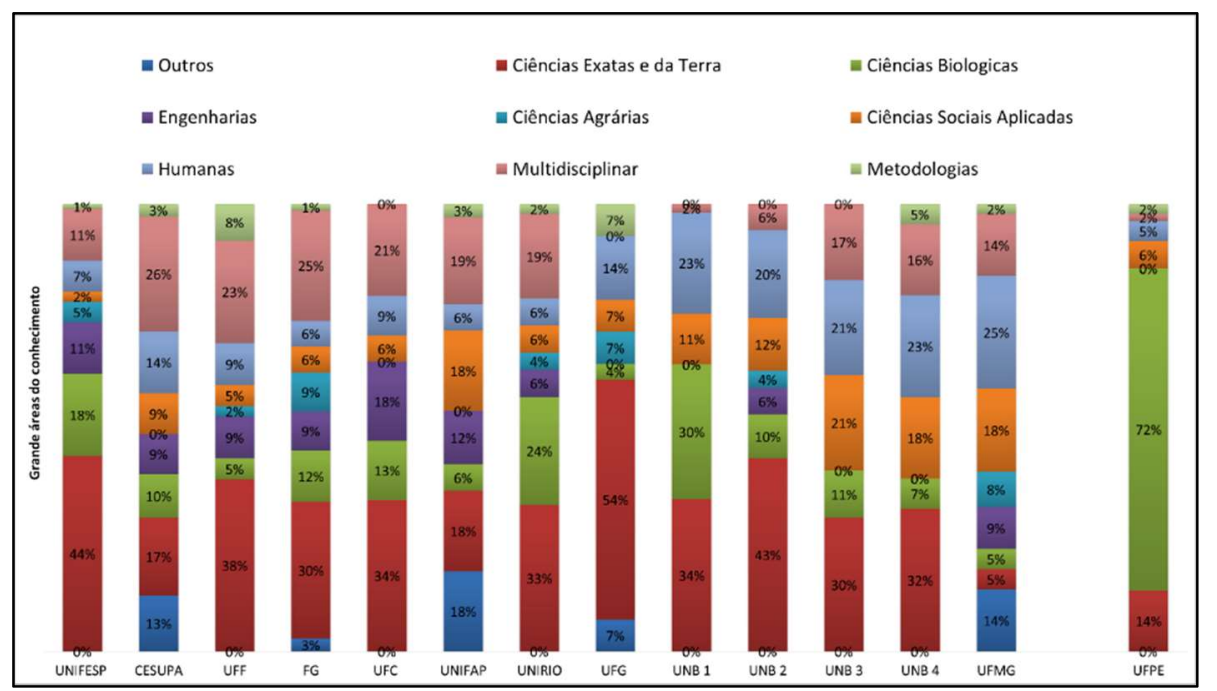

Figura 2: Gráfico da distribuição da carga horárias das grandes áreas do conhecimento segundo CNPq nos cursos de Ciências Ambientais nas universidades analisadas.

Em segundo lugar destaca-se a Multidisciplinar, possuindo em média 15,3\% da carga horária dos cursos, o que exprime a base conceitual para a formação do cientista ambiental, postulado para um profissional capaz de integrar equipes multidisciplinares. Em terceiro lugar, em uma situação mais ou menos equilibrada, destacam-se as grades áreas de Ciências Sociais Aplicadas, Ciências Biológicas e Humanas, respectivamente com médias de 10,11 e 14\% das cargas horárias dos para a grande parte dos cursos, cujas as variações dependem da ênfase da formação do curso, hora voltado mais para Ciências Sociais/Humanas ou Biológicas. Apenas para o curso da UFPE a carga horário para Ciências Biológica é de $70 \%$, destoando dos demais, por se tratar de um Curso de Ciências Biológicas com ênfase em Ciências Ambientais.

Para as demais grandes áreas: Engenharia, Ciências Agrárias, Metodologias, apresentam menores cargas horárias, respectivamente uma média de $10 \%, 5 \%$ e $3 \%$, em função das particularidades e da flexibilização curricular de cada Curso, norteados pela Lei de Diretrizes e Bases da Educação Nacional (1996). A categoria "Outros" possui uma média de mais de $40 \%$ de carga horária nos cursos contemplados, porém possuem características singulares como já apresentado. Para melhor entender o desenvolvimento curricular dos cursos de ciências ambientais, verificou-se o conjunto de disciplinas oferecidas em cada uma das grandes áreas do conhecimento acima analisado (Figura 3). Essas disciplinas foram elencadas em suas áreas de acordo com a proposta curricular de cada disciplina disponível nos PPPs, e não apenas pela nomenclatura da disciplina. 


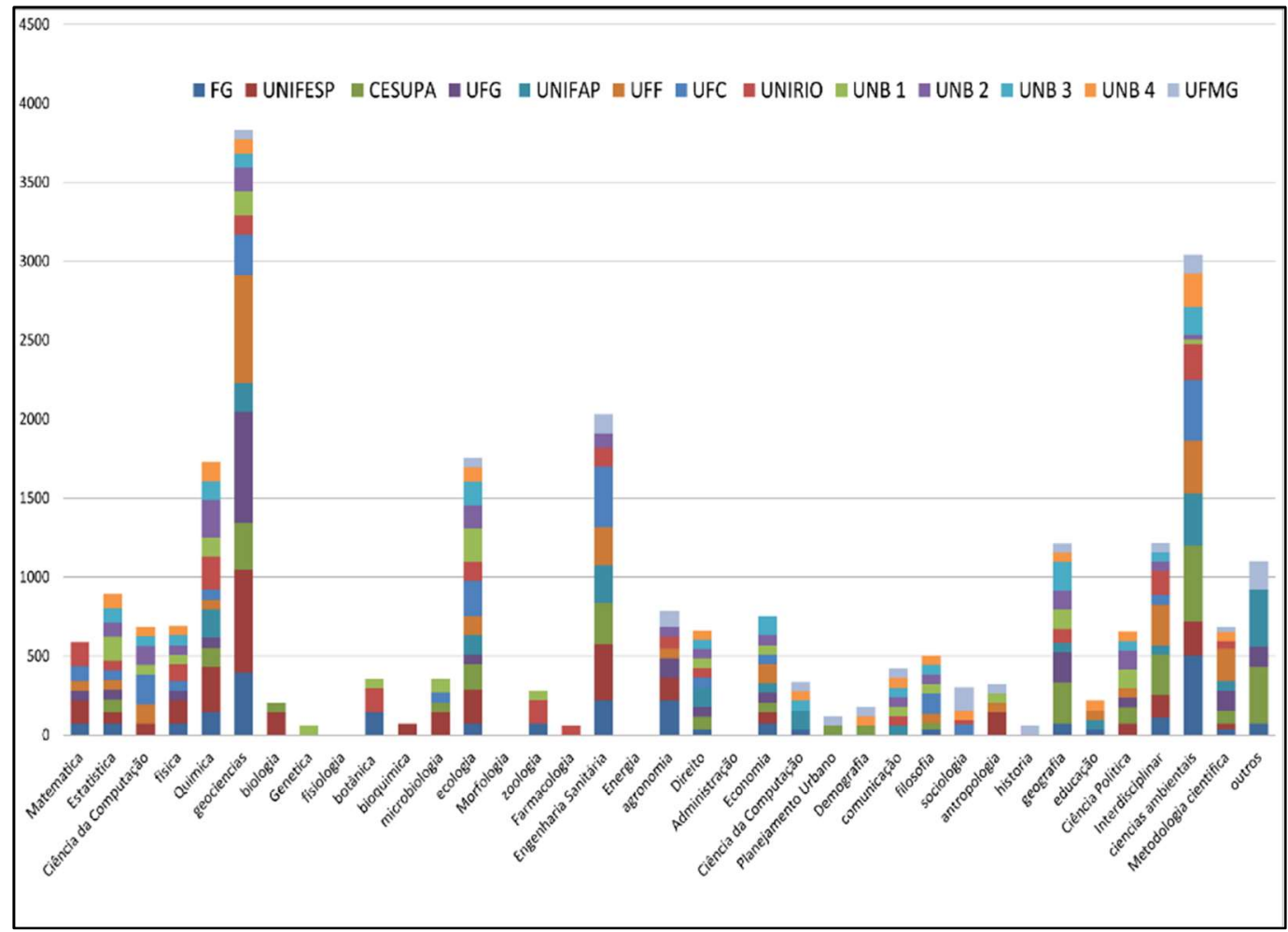

Figura 3: Gráfico da distribuição da carga horária das disciplinas das grandes áreas do conhecimento em cada Curso de Ciências Ambientais.

Para Grande área de Ciências Exatas e da Terra foram contempladas as seguintes áreas e disciplinas: na área de matemática as disciplinas de Matemática Aplicada e Cálculo I e II; na área de Estatística as disciplinas de estatística, Estatística aplicada, Análise de dados e Tratamento de dados ambientais; na área de ciência da computação as disciplinas de SIG-Sistema de Informações Geográficas, Instrumentação no Monitoramento Ambiental, Técnicas de navegação, Processamento Digital de Imagens, modelagem ambiental; para a área de Física as disciplinas de Física I e II e Física Ambiental.

Para a área de química, as disciplinas de Química Ambiental l e Il, Química da Água, Química Orgânica, Química Aplicada, Química Analítica, Química e Despoluição da Atmosfera e Fundamentos da Química I e II; na área de Geociências as disciplinas de Geoprocessamento, Mapeamento de Áreas Protegidas, Cartografia Geoambiental, Geoquímica, Geoquímica Ambiental, Mineração na Amazônia, Geologia I e II, Recursos Energéticos, Materiais Terrestres, Geodinâmica Externa e Interna, Geodiversidade, Geomorfologia, Origem e Formação da Terra, Hidrogeologia, Pedologia, Paleontologia, Ciências atmosféricas I e II, Climatologia e Mudanças Climáticas, Processos Físico-Químicos da Natureza, Ciclos Hidrológicos e Bacias Hidrográficas, Climatologia Ecológica, Ciência da terra I e II e Cartografia.

Para a grande área de Ciências Biológicas foram contempladas as seguintes áreas e disciplinas: na área de Biologia as disciplinas de Introdução à Sistemática Biológica e Ecológica, Sistemas Biológicos, Fundamentos da Biologia, Biologia Celular, Biologia da Conservação, Sistemática e Evolução e Biologia Evolutiva; na área de Genética as disciplinas de Biologia e Genética da Conservação, Genética de Populações e Genética; na área de Fisiologia as disciplinas de Ecofisiologia Vegetal e Fisiologia Animal.

Ainda sobre a grande área, mas mais especificamente para a subárea de Botânica, tem-se as disciplinas de Biologia Vegetal, Botânica, Dendrologia, Estrutura Vegetal e Diversidade Vegetal; na área de 
bioquímica as disciplinas de Biomoléculas, Biotransformações e Bioquímica; na área de morfologia, a disciplina de Anatomia Animal; na área de zoologia as disciplinas de Biologia Animal, Zoologia, e Diversidade Animal; e na área de farmacologia a disciplina de Toxicologia Animal.

$\mathrm{Na}$ área de microbiologia as disciplinas de Diversidade Microbiana, Biologia de Fungos, Transformações Microbiológicas e Microbiologia; na área de ecologia as disciplinas de Ecologia, Ecologia de Populações e Comunidades, Ecologia Aplicada, Ecossistemas Marinhos, Biodiversidade, Ecossistemas Aquáticos, Manejo Ecossistemas Marinhos, Reabilitação e Restauração de Ecossistemas, Estrutura e Funcionamento de Ecossistemas, Análise de Paisagens, Ecologia de Paisagens, Ecologia de Sistemas Marinhos, Ecologia de Águas Continentais e Ecossistemas Terrestres.

Para a grande área de Engenharias foram contempladas as seguintes áreas e disciplinas: na área de engenharia sanitária as disciplinas de Recursos Hídricos, Águas Subterrâneas, Ecologia e Manejo Florestal, Saneamento, Remediação Ambiental, Gestão de Resíduos Sólidos, Gestão de Recursos Florestais, Recuperação de Áreas Degradadas, Áreas Protegidas, Conservação da Biodiversidade, Conservação do Meio Ambiente, Descontaminação de Solo e Água, Poluição, Poluição Atmosférica, Tratamento de Efluentes Líquidos, Poluição de Ambientes Aquáticos, Fontes e Destinos de Poluentes e Poluição Ambiental; e na área de energia a disciplina de Fontes Energéticas e Nucleares.

Para a grande área de Ciências Agrárias foi contemplada a área de agronomia e as disciplinas de Manejo e Conservação do Solo, Relação Solo e Vegetação, Impactos Ambientais no Uso da Terra, Física e Conservação de Solos, Ciência do Solo, Estrutura e Dinâmica da Terra, Gestão de Agroecossistemas, Agroecologia, Solos e Paisagens, Ciência da Terra, Dinâmica Solo e Água e Espaço Agrário no Brasil.

Para a grande área de Ciências Sociais Aplicadas foram contempladas as seguintes áreas e disciplinas: na área de Direito as disciplinas de Filosofia do Direito e Meio Ambiente, Direito Ambiental Aplicado e Direito Ambiental; na área de administração a disciplina de Administração; na área de economia as disciplinas de Recursos não Renováveis, Meio Ambiente, Desenvolvimento e Economia, Economia Ambiental e Microeconomia Ambiental.

Ainda se referindo à grande área de Ciências Sociais Aplicadas, na subárea de ciência da computação, tem-se as disciplinas de Métodos e Técnicas Quantitativas, Métodos Computacionais Aplicados a Processos Ambientais, Economia Aplicada, Teoria Do Desenvolvimento e Economia do Setor Externo e Meio Ambiente; a área de planejamento urbano a disciplina de Urbanização e Dinâmica Urbana; a área de demografia as disciplinas de Demografia, Política Pública e População E Informática Aplicada; a área de comunicação as disciplinas de Redação Cientifica, Leitura e Produção de Texto, Métodos Qualitativos, Teoria da Comunicação e Expressão Oral e Escrita.

Para a grande área de Humanas foram contempladas as seguintes áreas e disciplinas: a área de Filosofia as disciplinas de Filosofia, Filosofia da Natureza, Epistemologia do Meio Ambiente, Consciência Cidadania e Meio Ambiente e Ética; na área de Sociologia as disciplinas de Sociologia, Sociedade e Meio Ambiente, Analise Socioambiental, Analise Sociológica e Ciências Socioambientais, na área de Antropologia 
as disciplinas de Povos Tradicionais, Antropologia Biológica, Etnobotânica, Etnobiologia, Antropologia Ecológica, Natureza e Cultura, Antropologia Cultural e Antropologia.

A subárea de História, a disciplina de História das Ciências; a área de geografia as disciplinas de Geografia, Cultura e Ambiente, Desenvolvimento Regional, Estudo da Paisagem, Geopolítica Ambiental, Espaço Regional Urbano e Meio Ambiente, Natureza e Sociedade, Meio Ambiente, Cultura e Sociedade, Patrimônio e Meio Ambiente, Biogeografia; na área de educação as disciplinas de Educação no Mundo Atual e Fundamentos da Educação; na área de Ciência política as disciplinas de Legislação e Políticas Públicas, Políticas Públicas, Governança e Meio Ambiente, Política Ambiental, Direito Ambiental e Políticas Públicas, Mediação de Conflitos Socioambientais, Políticas Públicas e Gestão Ambiental, Planejamento Público e Meio Ambiente.

Para a grande área Multidisciplinar foram contempladas as seguintes áreas e disciplinas: na área interdisciplinar as disciplinas de Gestão Ambiental, Empreendedorismo, Gestão Urbana, Gestão do Ambiente Agrário, Saúde e Meio Ambiente, Economia e Ecologia, Biossegurança, Ecologia Humana, Planejamento e Gestão Ambiental, Gerenciamento de Resíduo e Solo Contaminado, Gerenciamento Ambiental, Economia Política Ambiental, Saúde Coletiva, Produção e Ambiente, Sistema de Gestão Ambiental e Hidrodinâmica em Ambientes Aquáticos.

Na área de Ciências Ambientais, as disciplinas de Ciências Ambientais, Análise Custo Benefício de Projetos, História e Ambiente, Projetos Ambientais, Degradação De Biomas Terrestres, Zoneamento Ecológico e Plano Diretor, Análise e Planejamento Ambiental, Pericia Ambiental, Passivos Ambientais Amazônia, Tópicos Ambientais Contemporâneos, Auditoria e Certificação Ambiental, Planejamento de Investimentos Ambientais, Parâmetros Ambientais e Processos de Produção Industrial, Licenciamento Ambiental, Impactos Ambientais, Políticas e Unidades de Conservação, Ética e Educação Ambiental, Educação Ambiental, Ecologia, Política E Justiça Ambiental, Teoria dos Sistemas Ambientais, Estudos de Impactos Ambientais, Valoração Ambiental, Diagnóstico Ambiental, Riscos Ambientais, Crítica, Consciência e Cidadania Socioambiental, Políticas de Mecanismos de Desenvolvimento Limpo, Eco Empreendedorismo e Desenvolvimento Sustentável.

Para a grande área de Metodologias foi contemplada a área de metodologia cientifica e a disciplina de Fundamentos Trabalho Científico, Teoria das Ciências, Métodos e Técnicas em Pesquisas Ambientais, Elaboração de Projeto de Pesquisa, Metodologia do Trabalho Científico, Prática e Pesquisa e Metodologia Científica.

Quando se trata de transversalidade, Zucchi (2002), considera que a questão ambiental possui três qualidades fundamentais: a) serve como linha orientadora que cada curso/docente pode adaptar à realidade local; b) é um tema adequado ao trabalho com todas as faixas etárias; e c) é um tema "emergente e urgente" cuja abordagem ultrapassa a mera transmissão de conhecimentos.

O tema transversal "meio ambiente" trata das relações entre as questões ligadas ao ambiente e aos fatores políticos, econômicos, históricos e sociais. Tais questões criam campos de discussão sobre as responsabilidades humanas dirigidas ao bem-estar social e ao desenvolvimento sustentado, sob o ponto de vista da reversão da crise social em assuntos ambientais, que são de interesse de todos os cidadãos (TRAVASSOS, 2004). 
Nos cursos analisados, a abordagem transversal das ciências ambientais converge para um tratamento das questões relativas ao meio ambiente considerando seus elementos físicos e biológicos e os modos de interação do ser humano com a natureza, por meio do trabalho, da educação, da arte e da tecnologia. Na seleção dos conteúdos presentes nos cursos, seus proponentes se preocuparam em considerar sua natureza interligada às outras áreas do conhecimento e a necessidade de serem tratados de modo integrado, não só entre si, mas entre eles e o contexto histórico e social em que as universidades estão inseridas.

No entanto, esse enfoque transversal não é ainda de domínio pleno pelos professores, e nem existe um consenso do que vem a ser o seu objeto de trabalho. Isso coloca um desafio pedagógico aos cursos de Ciências Ambientais pois, segundo Zucchi (2002), o fato de os professores conhecerem os conteúdos de suas especialidade, não significa de maneira alguma que ele se comprometa com a abordagem transversal fundamental para a adequada visão das questões ambientais.

As áreas do conhecimento de matemática, estatística, ciência da computação, física, química e geociências fazem parte da grande área de Ciências Exatas e da Terra, nelas foram inclusas disciplinas como: Cálculo, Processamento de Imagens, Estatística, Física, Química, Geoquímica, Paleontologia, Climatologia, Ciência da Terra, entre outras. Nessa grande área se destaca a área de geociências como a área de maior carga horária de todas analisadas, que comporta a base das ciências da terra. As áreas de exatas mesmo que com menor carga horária quando comparada com outras mostra-se como fundamental para a formação do profissional dessa área, já que tem disciplinas em todas as universidades, disciplinas essa como Cálculo, Física e Química Básicos e Aplicados na Área Ambiental.

A grande área de ciências biológicas é composta pelas áreas: Biologia, Genética, Botânica, Bioquímica, Microbiologia, Ecologia, Zoologia E Farmacologia. As disciplinas alocadas nessas grandes áreas variaram com o perfil de cada universidade como pode-se observar no gráfico 2, exceto pela Ecologia que faz parte do grupo de áreas abordadas em comum para todas as universidades.

A grande área de engenharia foi representada nessa análise apenas pela área de engenharia sanitária devido as disciplinas abordadas como: Saneamento, Remediação, Gestão de Resíduos Sólidos, Áreas Protegidas, Conservação, Poluição Ambiental, entre outras. Abordada por quase todas as universidades é uma área que está associada às semelhanças que a graduação em ciências ambientais possui quando comparada com outros cursos como de engenharia ambiental.

As próximas áreas, como já dito anteriormente, fazem parte da liberdade das universidades ao construir seus currículos, são elas: Agronomia (da grande área ciências agrarias), Direito, Economia, Ciência Da Computação, Planejamento Urbano, Demografia, e Comunicação (da grande área ciências sociais aplicadas), e Filosofia, Sociologia, Antropologia, História, Geografia, Educação, e Ciência Política (da grande área de humanas), entre todas essas áreas destacam-se Agronomia, Direito, Economia e Ciência Política como áreas comumente ofertadas pela maioria das universidades.

A área de geografia é considerada como humanas nas áreas do CNPq, mas pela avaliação das disciplinas e ementas pode-se avaliar que sua forte adesão das universidades e considerável carga horária 
são pelas mesmas características da próxima grande área analisada que é a Multidisciplinar. Nessa última forma contempladas as áreas multidisciplinar e de ciências ambientais, com disciplinas de Gestão Ambiental, Saúde e Meio Ambiente, Biossegurança, Ecologia Humana, Gerenciamento Ambiental, Economia e Política Ambiental, Análise e Planejamento Ambiental, Auditoria, Perícia, Impactos Ambientais, Crítica, Consciência e cidadania Socioambiental, Ecodesenvolvimento, Desenvolvimento Ambiental, entre outras.

Essas disciplinas, além da significativa carga horária, são responsáveis pela caracterização do perfil desse profissional, pois elencam disciplinas que englobam os conteúdos pré-desenvolvidos durante os primeiros semestres do curso em todas as universidades, elas são de caráter inter e transdisciplinar, como o esperado. A grande área de Metodologias mostra a presença de disciplinas nessa grande área na maioria das universidades, isso explica-se, além do fato de ser um ensino superior e automaticamente exigir conhecimentos em metodologia científica, pela característica das universidades públicas em ter um viés voltado à pesquisa.

\section{CONCLUSÕES}

Apesar de não existirem as Diretrizes Curriculares para o Curso de Graduação em Ciências Ambientais no Brasil, a partir da análise apresentada é possível verificar quer os currículos dos cursos em atuação abordam áreas comuns de conhecimento como as Ciências Exatas e da Terra, Ciências Biológicas, Ciências Sociais Aplicadas, Humanas, Multidisciplinar e Metodologias, e ainda alguns se assemelham na incorporação de disciplinas na grande área de Metodologia, Ciências Agrárias e Engenharias.

Porém mesmo abordando grandes áreas do conhecimento em comum cada curso faz isso de maneira única nas proporções de carga horária e distribuição das disciplinas, sem considerar a abordagem de cada universidade mesmo em disciplinas semelhantes. Dessa maneira, seguem de forme concisa a proposta do curso de Ciências Ambientais em se dedicar a formar profissionais interdisciplinares de conhecimentos múltiplos e visões transversais das complexidades do meio ambiente e sociedade.

Seguindo a individualidade dos cursos provocada pela flexibilidade proposta na Lei de Diretrizes e Bases da Educação Nacional (1996), pode-se revelar nessa análise dos currículos dos cursos de graduação em ciências ambientais no Brasil as diferentes habilidades e competências na qual os alunos são contemplados nas diferentes universidades com experiências de acordo com o seu perfil universitário, como a UFPE que é voltada a área de ciências biológicas, a UFMG que tem seu viés para a área social, a UFG voltada a geociências, a UNB que se subdividiu entre 4 diferentes habilidades, e as outras que incorporam suas necessidades e preocupações específicas.

\section{REFERÊNCIAS}

ABRAMOVAY, R.. Construindo a Ciência Ambiental. São Paulo: Annablume, 2002.

BERTALANFFY, L. V.. Introdução. In: BERTALANFFY, L. V.. Teoria Geral dos Sistemas: Fundamentos, desenvolvimento e aplicações. 5 ed. Petrópolis: Vozes, 2010. p. 21-53.
BRASIL. Lei de Diretrizes e Bases da Educação Nacional. Brasília: MEC, 1997.

BRASIL. Lei n.9795 de 27 de abril de 1999. Dispõe sobre a educação ambiental, institui a política nacional de educação ambiental e dá outras providências. Brasília: DOU, 1999 
COUTINHO, M.. Ecology and environmental science in Brazilian higher education: graduate programs, research and intellectual identity. São Paulo: USP, 1996.

JAPIASSU, H.. Interdisciplinaridade e patologia do saber. Rio de Janeiro: Imago, 1976.

LEFF, H.. Complexidade, Interdisciplinaridade e Saber Ambiental. In: PHILIPPI JUNIOR, A.. Interdisciplinaridade em Ciências Ambientais. São Paulo: Signus, 2000.

NEIMAN, Z.. Era Verde? Ecossistemas brasileiros ameaçados. 24 ed. São Paulo: Atual Editora, 2013.

NOAL, F. O.. Os ritmos e os riscos: considerações sobre globalização, ecologia e contemporaneidade. In: CASTRO, R. S.. Sociedade e meio ambiente: a educação ambiental em debate. 3 ed. São Paulo: Cortez, 2002.
PIMENTEL, A.. O método da análise documental: seu uso numa pesquisa historiográfica. Cadernos de Pesquisa, n.114, p.179-195, 2001.

ROCHA, P. E. D.; MOREIRA, R. J.. Interdisciplinaridade na PósGraduação: Notas de pesquisas. Redes, v.7, n.2, 2002.

UNESCO. Organização das Nações Unidas para a Educação, a Ciência e a Cultura. Universities and environmetal education. Paris: UNESCO, 1986

UNIFESP. Universidade Federal de São Paulo. Projeto Pedagógico do Curso Superior de Bacharelado em Ciências Ambientais. São Paulo: UNIFESP, 2016.

ZUCCHI, O. J.. Educação Ambiental e os Parâmetros Curriculares Nacionais: um estudo de caso das concepções e práticas dos professores do ensino fundamental e médio em Toledo-Paraná. Dissertação (Mestrado em Engenharia de Produção) - Universidade Federal de Santa Catarina, Florianópolis, 2002. 